\title{
The Impact of the Implementation of the ERP on End-User Satisfaction Case of Moroccan Companies
}

\author{
Fatima JALIL \\ EM2TI \\ INPT: National Institute for Posts \\ and Telecommunications \\ Rabat, Morocco
}

\author{
Abdellah ZAOUIA \\ EM2TI \\ INPT: National Institute for Posts \\ and Telecommunications \\ Rabat, Morocco
}

\author{
Rachid EL BOUANANI \\ LIS \\ FSJESM: Faculty of Social and \\ Economic Legal Sciences \\ Mohammedia, Morocco
}

\begin{abstract}
In recent years, the implementation of ERP is as a lever for development and inter-organizational collaboration. The ERP is a powerful tool for integration, sharing of information, and fluidizing of the process within the organizations (El Amrani et al. 2006; Kocoglu and Moatti, 2010).

The company must not only equip and computerization but it must opt for the establishment of an IT infrastructure "optimal" who will respond to its present and future needs. OF or the interest of the application integration, and especially of the ERP who come remedy the situations mentioned. This article proposes a model and tests to evaluate the success of a system "Enterprise Resource Planning "(ERP) based on a measure of user satisfaction. Referring to the model DeLone \& McLean (1992) and the work of Seddon \& Kiew (1994). The criteria that can influence user satisfaction, to ensure the successful implementation of the ERP system are identified.

The results of the exploratory study, carried out on 60 users in 40 Moroccan companies, shows that user satisfaction of ERP is explained by the quality of the ERP system, perceived usefulness and quality of information provided by this type of system. The study also found that the quality of change is a predictor of satisfaction measured by user involvement in the implementation of ERP, the quality of communication within such a project and the quality of training given to users.
\end{abstract}

Keywords-Enterprise Resource Planning (ERP); User Satisfaction; Quality Change;Information Technology (IT); Information Systems(IS); success; evaluation approaches; Evaluation Success Factors

\section{INTRODUCTION}

The current context of global economic activity is characterized by a large and permanent competition as well as a large customer requirement for immediate and complex solutions. In this context, process control and continuous improvement become prerequisites for success. As a result, numerous companies around the world are trying to take advantage of an overhaul, using software packages, their information systems, and hundreds of them have opted for systems integrated management ERP (Enterprise Resource Planning) as a basis for the integration of their industrial management (Marbert, Soni \& Venkataramanan, 2000). [3]

The use of information and communication technologies (ICTs) such as ERP seems to be a great contribution to the profound changes in the functioning of companies. These packages make reference to information systems (IS) implemented to integrate the flow of information at the level of the entire organization. To achieve this integration between functional areas, ERP operate a centralized database that stores the collection and organization of data in "real time". Technological innovation of these software management can realize the old dream of the companies to have a single repository, and integrated their management information system (GIS) (Davenport, 1998) [4]; Rowe, 1999). Organizationally, the implementation of ERP is considered a change in the information system and in the process of guidance and control (Gomez et al. 2002). In fact, if many companies are attracted by the ERP, it is because this is supposed to make gains in productivity and efficiency, including the ability to make more integrated organization. This integration concerns both automated business processes that information processed by the software (Perotin, 2002). [5] Indeed, integration is placed among the main reasons companies to equip an ERP (Marciniak 2001).

Lequeux (1999) [6] defines the ERP system as "a subset of the IS able to take over the complete management of the company, including accounting and financial management, production management and logistics, managing human resources, administrative management and the management of sales and purchases. "

In other words, Perotin (2002) argues that the ERP system is defined as all "configurable and modular software applications, designed to integrate and optimize business management processes by providing a single repository and consistent and based on standard business rules". However, these systems are, in many cases, adopted without their suitability to the organizational context of the company is evaluated. Hence their implementation could result in low levels of user satisfaction, and therefore low levels of success. Moreover, these companies do not have often adequate tools that allow them to evaluate these systems and whether they meet the needs of individuals who use them.

The change must be seen as a solution enabling the organization to respond to quality management problem and adapting to look as well as its environment itself (Florescu Dumitru \& 2007). A driving change plan is able to reduce resistance now. This study is interesting on two levels:

- The objective of this article is therefore to identify the drivers of satisfaction of users of ERP systems. On a finer way, we try to determine the satisfaction and enhance the need for good conduct ERP projects to 
increase the degree of the satisfaction. To do this, it was reduced to build a model for the explanation of this satisfaction.

- In what follows, we will try to review the state of the art in measurement of user satisfaction of IT before submitting the research model and the results of an exploratory study conducted with a sample of Moroccan companies.

\section{ERP AND ITS CONTRIBUTIONS FOR USERS}

The evolution of computing, which is progressing towards greater information sharing and flexibility is a key factor explaining the growing success of ERP to companies. Despite the unquestionable progress they make today, ERP do not fully meet satisfactorily the needs of companies.

\section{A. The emergence of integrity management software}

Historically, functional systems businesses were developed on different materials following different methodologies: the achievements are generally heterogeneous both in terms of data representation at the level of processing modes. It follows multiple disadvantages:

- Communication problems between areas expected to share common data;

- Process control challenges due to the multiple treatments required to obtain synthetic statements;

- Students maintenance costs in the absence of modularity resulting low scalability;

- Complexity of the training was the use of very varied software;

- Difficulties for many controllers, in the collection and rekeying data from different systems and serving to consolidate budgets, develop reporting tables, etc.

Faced with these recurrent difficulties, software companies and large consulting firms offer a single answer in the form of integrity management software to improve the overall consistency while allowing modularity.

\section{B. What is an ERP?}

Acronym of American origin, ERP (Enterprise Resource Planning) is commonly used to designate the integrity management software. The term "ERP" is not totally adequate because it puts only evidence planning appearance. However the French translation "ERP" does not include the planning dimension and its use is problematic.

As defined by Robert Reix (1999), an ERP is a computer application that incorporated the following general characteristics:

- An ERP is a software package: according CXP4, a software package is "a coherent and independent set is service programs, supports, or handling of information and documentation, designed to perform standard IT processes, including the distribution is of a commercial nature and that a user can independently use after installation and limited training "(Sourdeau 1997, p20).
- An ERP is customizable: standardized product, the ERP is designed originally to meet the needs of various businesses. II usually are different versions by sector (automotive, banking, etc.) and prolonged use. In addition, the adaptation of the product to the needs of a particular business is by setting (choice of management rules, choice of treatment options, choice of data format, etc.). The setting may be accompanied by an appeal has additions of specific programs articulated around standard programs.

- An ERP is modular: it is not a monolithic structure but a set of programs or separable modules each corresponding to a management process: installation and operation can realize autonomously. The division into modules allows you to dial a specific solution for assembly and extend the implementation has different areas of management.

- A ERP is integrated: the various modules are not designed independently they can exchange information according to patterns provided. The PGI guarantees at all times a perfect integrity and data consistency for all users, allowing DC to end interfacing problems, synchronization and double entries.

- An ERP is a management application: it captures the company's transactions (accounting, stock management, order tracking and production program ...) and propagates the information collected to the appropriate levels. However, it contains no optimization program or automatic decision.

\section{Literature review on approaches, models and frameworks ERP success}

This part focuses on literature research is the success to summarize the two theoretical backgrounds and empirical studies. The presentation will be followed chronologically in terms of frames, models and approaches developed in the IS field. Then we will focus our attention on ERP as the main subject of this study. A review of the measurement of different approaches regarding the assessment of the success of ERP will be discussed to highlight the importance of the measure in the information system and in particular the ERP software.

\section{1) successful frameworks for the evaluation of ERP}

Development of a framework is the first step in the success of the assessment which must be adapted to the characteristics of the information system (Chand et al., 2005 [7]; Irani et al, 2014 [8]; Stefanou, CJ, 2001 [9]; Uwizeyemungu and Raymond, 2010 [10]) many frameworks have been proposed taking into account several phases and dimensions of evaluation of the system's success: strategic, tactical and operational. Generally, the framework describes eight categories: theoretical basis, the research approach, the object of analysis, the unit of analysis, the prospect evaluation, data collection, data analysis and type methodology (Urbach and Smolnik, 2008) [11]).

\section{2) The PAC Setting}

A proposal CPC could be considered an important framework for assessing the success of the ERP system because it incorporates three major dimensions part of the evaluation: content, context and process (Irani and love, 2008, Irani, 2002; Song and Letch, 2012). This framework was developed by (Irani and Love, 2008; Irani, 2002) [12] to help 
managers and decision makers in the process of assessing the benefits of IT / IS. They argue that there is not a good framework to evaluate the impact of IT in the performance of the organization in the literature and they added that there is no good framework to select appropriate tools for IS investment. For these reasons, they try to offer a CCP framework for assessing the cost and benefits based on three concepts: Content, context and process. But we conclude after analyzing this framework it is too big and general to be applicable to conduct an evaluation of the success of the ERP system.

\section{3) framework Stefanou}

Part of Stefanou consists of four phases: the first considers the vision of the company as a starting point for ERP integration. The second phase focuses on the needs of business and the company's ability to support and adapt the ERP system. The third phase requires estimation of the costs and benefits of integration of the ERP system. The last phase refers to the analysis of issues related to the use ERP, maintenance and evolution.

The product quality is one of the most important of the ESF in the project; in this case, the quality of the product means that the quality of the ERP system. Many measures are proposed to assess the quality such as response time, convenience of access, implementation of user requirements, error correction, data security and models, system integration, system flexibility the effectiveness of the system, database content, data currency, correctness and accuracy of the data system (DeLone and McLean, 1992).

\section{4) Soh and Markus framework}

The ultimate goal (Markus and Tanis, 2000; Soh and Markus, 1995) that works is to create a new framework that allows a better understanding of the concept of ESS (Enterprise System Success). Answering these questions: how companies can successfully integrate this technology? And what can we do to improve the chances of success? Authors define the result of success as a multidimensional concept, a dynamic concept, and a report (the concept of "optimal success," that represents the best of an organization can hope to achieve with enterprise system). P. 184.

Success can be defined by (Markus and Tanis, 2000) in terms of implementing the project, or in terms of business results. The first definition answers the question: the company managed to get the system running within some reasonable budget and schedule? The second answers the question: the company has managed to achieve its business objectives for the project?

Based on the theories of fusion process because (Markus and Tanis, 2000) consider that these theories combine both objectives and actions with the external forces and luck. They build their frame on a process designed by including emerging theory (Soh and Markus, 1995) to explain how the system of the company as a technology creates business value in organizations.

\section{The measurement models of successful ERP system}

Many models have been developed to evaluate the systems and the success of technology (Davis, 1989b; DeLone and McLean, 20031992 Gable et al., 2003; Ifinedo and Nahar,
2006; Sedera and Gable, 2010; Shang Seddon, 2002). These models have been validated empirically by numerous studies in the information system. The results show that many case studies are studied by applying the DeLone \& McLean model success using a modeling approach structural equation (Dörr et al., 2013).

However, these models assess the success of three levels of impact. The first is an individual impact (Davis, 1989a) that lights on user behavior. The second level is the group of impact (Gable et al., 2003; Sedera and Gable, 2010) interesting on the working group and its influence on performance, and the third is an organizational impact (DeLone and McLean, 1992)[1]. While one model could evaluate more than one level of impact, for example, and DeLone McLean model takes into account two levels of impact, individual and organizational performance. (Gable, et al., 2003; Ifinedo and Nahar, 2006; Sedera and Gable, 2010) in their models on the success of the extent of ERP, they take into account three levels of impact, the individual impact, 'workgroup impact and the impact of the organization to evaluate the success of the ERP system. Finally Davis in his model of technology acceptance model TAM takes into account a level; individual impact to assess the user perception and behavior.

\section{1) Acceptance Model Technology TAM (Davis, 1989)}

This model has been widely used in the information system and considered one of the main theoretical foundations (King and He, 2006). TAM has proven to be one of the most powerful models to explain user acceptance of the technology and user behavior (Wu et al., 2011). Davis says that the use of technology is determined by two factors, perceived usefulness and perceived ease of use, this individual impact is the main purpose of the technology acceptance model. Many studies apply this model to understand the behavior and attitude of the users of the ERP system and assess the satisfaction following use of the system, measuring the latter to use the ERP system is CST Computer Self-Efficacy (Bradford Florin, 2003; Kwahk and Lee, 2008; Scott and Walczak, 2009).

\section{2) DeLone and McLean model of success}

$\mathrm{D} \& \mathrm{M}$ is the model city in the success of the information system (Kronbichler et al, 2010; Sedera and Gable, 2010); it is one of the most famous models adopted by researchers to measure success the information in the last two decades system. (Seddon, 1997) in his article respecification extension and D \& M Model of the SI, criticized this model about the inclusion of both causation and process interpretations, which lead to the significance of the confusion reduce the value of the model (Seddon, 1997). DeLone and McLean have updated their model based on these criticisms (Delone and McLean, 2003). Despite this update their model, the first version adopted and remains the most cited in the literature review is a success.

The strength of D \& M model is its theoretical foundation based both on Shannon \& Weaver communication theory and communication systems approach Mason (Mason, 1978; Weaver and Shannon, 1949). They claim that information is considered as an output of an information system that can be measured at three main levels: technical, semantic level and efficiency, referring to the mathematical theory of 
communication (Weaver and Shannon, 1949) and its levels to analyze the message following the communication system. Defining and measuring the output of any system is always difficult, especially if the output is rather intangible nature. Information output is represented in symbolic form, the concept of signs is essential to both the information and communication; it is considered a single system the key link in the way affect the other, and involves the system context and the sign its self (Mason, 1978)[13].

Based on these theoretical foundations, D \& M developed six categories or aspects of information system that will become the construction of their separate model, these constructions are: system quality (SQ), information quality (IQ) USE, user satisfaction, individual and organizational impact Impact. These variables are most adopted in measuring the success of information in the last two decades system. However, the problem is the model building that tries to combine both causal processes and explanations of IS success (Seddon, 1997) [14]. The result of the combination of variance and process model is that a lot of boxes and arrows may have both a variance and an event in a process of interpretation, giving a feeling of different parts of the model will cause slippage of a direction arrow in a box or another (Seddon, 1994)[2], the subsequent claim that the major difficulties with D \& M model can be demonstrated by drawing attention to the use as a construction. This box can take three possible meanings: as a variable that proxies for the benefits of using as the dependent variable in a model variant of the future is to use and thirdly as an event in a process leading to the individual or organizational impact.

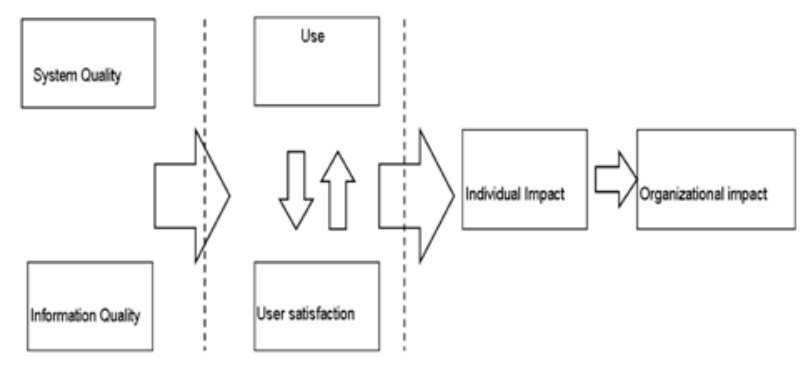

Fig. 1. D\&M IS Success Model (Delone\& McLean, 1992)

Seddon shows the meaning of the categories in DeLone \& McLean model is successful, and explains the combination of three types:

- A model of the variance is success, where quality system and quality of information are considered as independent variables and the dependent variables are the East use and user satisfaction.

- The second model is a variance model to use as a behavior, which can take a second meaning, is to use

- The third model is a process model, where the use is considered an event necessarily precedes the following constructions: the user satisfaction, individual impact and organizational impact. (Seddon, 1997).

Beyond the combination of the two dimensions of causality and processes to explain the construction and confusion in the direction of D \& M model (Seddon, 1997) other considerations would occur as the level considered to explain the success of an information system and the impact on performance. Success is the evaluation is not limited to internal factors according to $\mathrm{D} \& \mathrm{M}$ in their model based on the theory of Shannon and Weaver. For example the quality of the ERP system is not only a causal variable leading to success, but can also be seen as a result of other external factors, such as organization, innovation, and environmental factors (Bradford Florin, 2003; Ifinedo, 2011[15]; Sedera and Gable, 2010)[16].

\section{E. evaluation approaches}

Many researchers have tried to understand the relationship between IT investments and performance, focusing on five main approaches for evaluating IT projects (Bellaaj, 2010) [17]. These approaches are:

- Evaluation Approach economic theory (Brynjolfsson, nd): the main objective of this approach is to understand the gap between IT investment and productivity of the organization according to certain economic criteria.

- Evaluation Approach Social Psychology (Davis, 1989a, 1989b; Venkatesh et al., 2003)[18]: beyond the economic approach, it incorporates the human factor as a key factor in the process of IT investment and impact assessment.

- Evaluation Approach Based on the analysis of competition: this approach is developed by (Porter and Millar, 1985) explains how technology affects all business. The authors outline the information technology needs to be understood more than just computers, it must be broadly conceived to encompass information that companies create and use as well as a wide range of technologies more increasingly convergent and linked this process the information in their perception of IT they adopt the concept of the value chain to explain the competitive advantages of IT investments.

- Evaluation Method based on strategic alignment: This approach is developed by (Henderson and Venkatraman, 1993), it is widely used by researchers in the information to understand two key concepts system; the first is the adequacy of the information technology goals and strategic objectives of the organization; the second is the functional integration (integration between business and functional areas). This approach suggests that the IT strategy must be consistent with the business strategy to improve organizational performance.

- Evaluation Process Approach: a new conception of assessment Is success was brought by this approach based on the theory developed by emerging process (Markus and Tanis, 2000; Soh and Markus, 1995) [20]. This approach highlights the failure of the economic model to assess the success, and proposes a new vision of evaluation not only on the input evaluation (assessment of IT investments) on the base, but also based on the use and impacts of IT, by virtue of a valuable creative process. 
Three main approaches could be considered to assess the success of the ERP system; the first is based on the financial performance criteria (Nicolaou and Bhattacharya, 2006)[19] to assess the benefits of ERP (tangible benefits), the second approach is based on the non-financial approach to evaluating the intangible benefits system ERP, and the last is a mixed approach, for example to assess the ERP system, many perspectives measurement must be taken into account, such as behavioral perspective (user acceptance), the strategic perspective (alignment between strategic organizational goals and ERP), the economic perspective (cost, expenses ..) and (Fit and organizational integration of ERP system) technology perspective. These four dimensions of evaluation of ERP were treated separately in the literature on measuring the success of the ERP system.

In this section, we present two examples of evaluation approaches that synthesize the different perspectives of assessment mentioned above. First, we will propose an AHP approach to assessing performance measures ERP (Tsai et al., 2006) [21]. Second, we will introduce the Balanced Scorecard approach widely adopted by many researchers to assess the benefits of the ERP system (Chand et al., 2005; Rosemann and Wiese, 1999; Velcu, 2010).

1) AHP approach to performance evaluation of ERP

The approach AHP (Analytic Hierarchy Process approach) is to assess the relative importance weight measuring the performance of the ERP; it can be used to select key performance indicators of the ERP system, and explains the contribution of the ERP system in organizational performance (Tsai et al., 2006). This approach is applied to problems of decision making to choose the best and appropriate according to the importance of each alternative. In the case of the ERP system two stages were presented by (Tsai et al., 2006) to assess the relative importance of performance measurement of ERP. The first is to list all performance measurement ERP and assessing their importance. The second stage focuses on building a framework for analysis and AHP achieve weight relative importance of $80 \mathrm{ERP}$ performance measures using a questionnaire with Likert-type scale 7 points $(1=$ very little importance, 7 = extremely important).

This approach focuses the post-ERP implementation phase. Based on D \& M model 1992, this approach provides a new taxonomy of performance measurement: the category of quality, and class of measuring impact. Quality concerns the ERP system information, system usage and user satisfaction, impact category covers both individual and organizational levels. The result of this study shows that a company can select specific performance metrics based on three main factors: the objectives of its ERP system, and the specific needs of the business context. This means that each company must build its primary measure of performance, taking into account three main factors mentioned above.

2) Balanced Scorecard approach to measuring the performance of ERP

This approach is developed by (Kaplan and Norton, 1992)[22] to better understand and classify measures of organizational performance. They claim that the balanced scorecard enables managers to analyze business performance from four perspectives, the financial perspective, the internal business perspective, the perspective of innovation / learning and finally customer perspective. This part of BSC is widely used in management science in various disciplines to assess organizational performance. However, our focus is on using this approach to evaluate the performance put up by the ERP system. Some researchers have been interested in this question about the evaluation of the performance of the ERP system in a BSC approach (Rosemann and Wiese, 1999; Velcu, 2010). They explain how the BSC approach can be used to evaluate the performance of the company set up by the ERP implementation at both operational and strategic levels.

This application of the BSC sheds some light on understanding the three levels of ERP impact on performance at the operational level, tactical level and strategic level. These levels provide a framework for the analysis of benefits based on the strategy and organizational goals ERP system throughout the ERP lifecycle.

\section{F. The theoretical foundations}

First, we present our conceptual model which is based on both theoretical and empirical background. This framework will be considered a success evaluation model of ERP system that combine causal processes and considerations for evaluating the success of the ERP project in three performance levels: The individual performance, the performance of the task force and performance Organizational (and Ifinedo Nahar, 2006; Ifinedo 2011; Ifinedo et al, 2010; Myers et al .., 1997). The levels of analysis included in this model were based on three theories: the first theory is the mathematical theory of communication used by DeLone and McLean is a success model to analyze the quality of the system and its impact on quality information on the one hand, and the impact of the quality of information in the efficiency users, on the other hand; The second theory is the theory of diffusion of innovation used to analyze and classify the different factors in three main boxes: innovation factors, organizational factors and environmental factors; and finally the theory of the structure to analyze the contribution of the ERP technology in organizational performance.

\section{1) Mathematical Theory of Communication}

The mathematical theory of communication (Mason, 1978; Weaver and Shannon, 1949)[23] explains the interaction of three factors: the information system, information such as a product and the impact of information on individual performance and organizational. This approach is used by (DeLone and McLean, 1992) in their model of success for developing sexual constructions considered the main variable to evaluate the success of the information system.

\section{2) Innovation diffusion theory}

Based on the theory of diffusion of innovation, mainly paradigm variables determining the adoption of innovation (Rogers, 1983)[24], three main factors emerged: Innovation / Technological factors, environmental factors and factors Organization. In this taxonomy, each of these factors can be explained in the context of the ERP system. These factors are extremely important in the adoption of ERP phase and they must be integrated in the process of successful ERP system (no success without adopting one hand technologies). 


\section{3) Structuring theory (AST approach)}

Structuration theory associated with institutional theory Giddens social assessment has been widely applied to understand and explain organizational technology adoption (DeSanctis and Poole, 1994) [25]. We focus solely on the AST proposed by DeSanctis and Poole, 1994 to explain how technology brings productivity, efficiency and satisfaction to both individuals and organizations. This approach is based on the school of technology was applied and explained by DeSanctis and Poole, 1994 in their approach to the theory Adaptive Structuring. The ASP is considered a framework to study the variation in the change of the organization and illustrating the impact of advanced technology on organizations. It has been tested on a GDSS (Group Support System to the decision) to answer questions about how technology affects people and organizations that use it, and how it improves the performance of the working group.

We consider this approach AST as an extension of the determinant variables paradigm adopting the technology because the technology adoption is an important step in the process of ownership leading to improve performance in the top three levels (individual, group and organizational performance). (Desanti and Poole, 1994) stress the importance played by the members of the organization in the process of choosing the most appropriate technology.

\section{DeVELOPMENT OF A Model SEARCH}

While ERP systems generate several technical problems: integration of ERP solutions with existing applications (legacy systems) or new business software (eg SCM Supply Chain Mangement, Electronic Data Inter exchange EDI ...) but mainly managerial issues regarding aspects related to the cost, the project period and company organization.

Therefore, if a company wants to incorporate an ERP system, even though its operations are not integrated, it should not, alone, buy a software package and associated computer equipment but it is called, also, to acquire know-how and establish a suitable organization of work.

Therefore, methods of effective use of ERP systems require something other than a good computer. Moreover, several companies say they face serious difficulties in the implementation of an ERP system without the technical aspects are actually involved: this is due, in fact, to disregard and neglect human and organizational factors (Anonyme1, 1997).

Thus, and in support of some researchers (Bancroft, 1996; Kaemmergarrd \& Moller, 2000)[26], the factors considered can be classified keys to the success of an engineering change under the under the following dimensions: the involvement of management Generally, user involvement, communication management, training and the implementation strategy that includes both reengineering business processes (BPR) that the same approach of implementation of these systems.

ERP, adding a new dimension, which includes the sub dimensions listed above, turns out advisable to measure user satisfaction of the TSI, including ERP.

At the basis of this reasoning, it is assumed that an ERP system is effective at the individual level where its users are satisfied. This level of satisfaction is determined by the quality system implemented in the company, a good quality of the information it provides, high value perceived by users and good engineering changes necessary for its implementation.

Thus, the various built the model proposed for measuring user satisfaction of an ERP system, detailed below, may be diagrammed as in Figure 2.

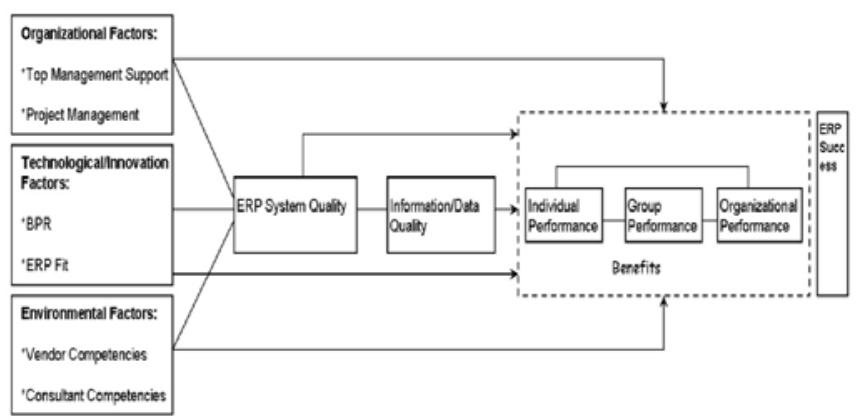

Fig. 2. The conceptual model of measuring user satisfaction of an ERP system

\section{DEVELOPMENT HyPOTHESIS}

This dimension has been used extensively in the literature as the dependent variable success SI. DeLone \& McLean (1992) fall within a number of 33 empirical studies published between 1981 and 1987 who enjoy success in terms of user satisfaction (Bailey et Pearson, 1983; Ives, Olson \& Baroudi, 1983; Doll \& Torkzadeh 1988 ...).

Melone (1990)[27] stated that there is no consensus on a conceptual definition of the construct of user satisfaction. Indeed, user satisfaction has been associated with many terms such as "need felt", "acceptance of the system," "perceived usefulness", "appreciation of MIS", "feelings" (Ives, Olson \& Baroudi, 1983).

In general, this satisfaction was defined by "the attitudes and perceptions" (Lucas, 1975). In specifically, this satisfaction was defined as the result of the evaluation that individuals are on continuum "content - dissatisfied" (Naylor, Prichard \& Ilgen, 1980); or the sum of feelings and attitudes towards each of a variety of factors affecting the situation (Baiely \& Pearson, 1983).

However, it should be noted that the definition proposed by Seddon \& Kiew (1994) will be the one used for this article because the items related to the "user satisfaction" dimension of their work will be adopted. Thus, satisfaction is defined as feeling "net" of pleasure or displeasure that results from an aggregation of all the benefits that a person hopes to receive from the interaction with the information system (Seddon \& Kiew 1994).

\section{A. Quality system erp}

This dimensión is widely used in the literature (Doll \& Torkzadeh, 1988; Davis, 1989; DeLone \& McLean, 1992; McGill et al., 1999; etc.). It is a powerful determinant of the 
effectiveness of IT as well as user satisfaction. The quality of the system relates to the quality of application itself (the different system functionality, ease of use and learning). In addition, it summarizes some issues such as the lack of "bugs" in the system, the user-friendly interface, etc. Therefore, the hypothesis H1 states: "The better the quality of the system (ERP) is good, more satisfaction is high."

\section{B. Quality of information provided by the system erp}

The concept of quality of information has been widely used as a key success factor in research in SI. In fact, this construct has been measured primarily by Bailey \& Pearson (1983) and Doll \& Torkzadeh (1988) as a measure among other satisfaction. This dimension usually includes attributes related to the quality of the information provided by the ERP system, such as the format of the information, clarity of information, accuracy of information, availability of necessary information in real time, the information content, etc. Therefore, the second hypothesis H2 states: "The better the quality of information provided by the system (ERP) is good, more user satisfaction is high."

\section{Perceived utility}

This construct is defined by Davis (1989)[28] as the degree to which a person believes that the use of a particular system would increase the work performance. This dimension has been considered as a factor affecting the satisfaction of users that it comprises, on the one hand, items related to the perceived ease of use and, on the other hand, those related to the perceived usefulness. Moreover, Davis (1989) shows that the acceptance of a technology depends on perceptions of users of this technology. Indeed, the Technology Acceptance Model (MAT) assumes two types of beliefs, perceived ease of use and perceived usefulness, determine the intent of the individual who influences the use of technology. This allows, therefore, bringing forward the third hypothesis $\mathrm{H} 3$ namely: "The greater the perceived usefulness by users, the greater their satisfaction is high."

\section{Quality of change}

As shown above, this new dimension can be understood by the five under following detailed dimensions.

\section{1) Involvement}

To drive change caused by the implementation of an ERP system, it is essential that this project will become the project of the entire company: from top management to operational (Mckerise \& Walton, 1995; Bingi, Sharma and Godla 1999; Rivard, 2000; Tomas, 1999; etc.)

\section{a) The involvement of senior management}

Indeed, the leaders are not called, only to finance the project but also to take an active role in managing change (Bingi, Godla and Sharma, 1999). This role is mainly to guide the overall operation, encourage local initiative, indicate very clearly the kind of organization that wishes to establish, define the corresponding steps of achievements, etc. (Mckerise \& Walton, 1995).

\section{b) The involvement of users}

Added to the commitment of senior management and middle management, the implementation of an ERP system can be conducted only by the involvement of the community of operational users and a user project manager full time representing the whole of this community (Tomas, 1999).

However, it is important to note that the involvement of users could not be, in itself, a prerequisite for the proper conduct of change. The latter requires, in addition, good communication management.

\section{2) Communication}

Certainly, the quality of communication within work groups plays an important role in employee attitudes towards change. Where communication and atmosphere were good, new technologies were generally welcomed with enthusiasm, while in groups where members felt compelled to comply with the new rules, reactions were much less favorable. In fact, communication is essential not only to create an understanding and approval of the establishment, but also to win the agreement of users. This communication should begin early, be consistent and continuous (Kaemmergarrd \& Moller, 2000).

In addition to good communication during an implementation project of an ERP system, it is inevitable to provide training to users.

\section{3) Training}

Training is seen as an important factor to facilitate change in the organization and introduction of new technologies (Mckerise \& Walton, 1995). This training aims mainly to prepare staff and help them adapt to their new tasks in order to be successful organizational change. It is not intended; only use new systems but also the understanding of new processes and their integration into the system. Hence, training is an ongoing process and updating a challenge (Bingi, Godla and Sharma, 1999).

\section{4) The implementation strategy of an ERP system}

The implementation of an ERP system means a continuous learning cycle in which the organizational process supported by ERP systems is aligned gradually with the company's goals. Lequeux (1999) says: "Far from leading a purely IT project, the adoption of ERP should be an opportunity to reconsider the mechanisms and improve the flow participating in the operation of the business, even to consider a business process reengineering or BPR, Business Process Reengineering ".

\section{a) The Business Process Reengineering (BPR)}

Moreover, the re-engineering of business processes and implementation of ERP systems are inseparable. They should be carried out simultaneously in order to obtain the best fit between the technologies and processes. This adjustment requires considering the role of ERP systems such as infrastructure, which now support the process and no longer functions and, therefore, improve their organizational effectiveness.

\section{b) The ERP system implementation approach}

Akkermans and Helden (2001) have focused on ERP systems implementation approach while trying to show that the incremental approach, scalable, based on continuous improvement is a key success factor in the implementation of a project ERP. They add that users of an ERP system are less satisfied if there was a radical approach (Revolutionary) that 
this approach results in a rigid management style based on a high degree of control and command, Intensive use of external experts, even non staff involvement and therefore a loss of skills and know-how internally. Thus, and from the previous development on engineering changes, it was agreed to present the hypothesis $\mathrm{H} 4$ on this new dimension, "the higher the quality of engineering change is good, more user satisfaction is better ".

This hypothesis derived secondary hypotheses for sub dimensions of engineering change. They are formulated as follows:

- H4a "More DG is involved in the project implementation of an ERP system, more user satisfaction has increased."

- H4b: "More user involvement, the greater their satisfaction is high."

- H4c: "More communication is good, most users are well satisfied."

- H4d: "More training is good, more user satisfaction is very high."

- H4e "The incremental implementation approach can increase user satisfaction more than the radical approach."

\section{RESEARCH METHODOLOGY}

Once part of the research is defined and the variables of the research are identified, it is important to conduct data collection. For this, a questionnaire, multi-scale, was built and tested with users belonging to both different hierarchical levels as various services, and finally administered face to face in Moroccan companies.

Given that companies have adopted ERP systems are not numerous, it was not possible to focus on a specific industry. The selection of the study population was guided by a single criterion, namely: the existence of an ERP system that is already operating at all levels (all modules are already functional) or at least a good part of the system east. The different ERP vendors (Oracle Applications (Oradist), MFG/Pro (DISCOVERY) ADONIX X3 (STAR ENGINEERING), JDEdwards (LPI)) are chosen as the starting point for the definition of the population.

Data collection has collected a sample of 40 companies surveyed; representing an effective response rate (60.45\%). However, it should be noted that the unit of this study is defined as the user of an ERP system. Therefore, the respondent is either the project leader or the leader or one of the senior or middle managers, or one of the last entry clerks. What mattered was the use of the ERP system.

\section{RESULTS AND INTERPRETATION}

It is important to note that the measurement scales were either adopted from previous work or created for the need of this research.

\section{A. Descriptive analyzes of research variables: evaluation of measures}

After proposing measures to the various concepts identified in the model and collected the data from the selected population, it is appropriate now to ensure the quality of these measures before making adequate statistical treatment. To do this, we made two types of tests for evaluating the measures namely: tests

On the dimensionality and reliability test (Cronbach's alpha) (Evrard, Pras \& Roux, 1997). Through these purification tests, which are based on principal component analysis ACP was determined for each building its KMO MSA and each of its items.

So we tried to conclude whether built or not is one dimensional and to specify the contribution of each item to the formation of the factor. Finally, we calculated, for each cleared factor, Cronbach's alpha.

\section{B. Explanatory analyzes of research}

Once the measures have been evaluated and the new structures are identified, we proceeded to test hypotheses. This part, devoted to the operationalization of the model and test hypotheses, has identified the following results.

Results thus obtained confirmed the work of DeLone \& McLean and those Seddon \& Kiew. These results have shown that this satisfaction is explained:

- Primarily by the quality of the system, the quality of information provided by this system and the utility perceived by the users;

- Partially by the quality of engineering changes needed to implement the ERP system. It is true that the data analysis performed could provide only partial verification of this dimension engineering change because, firstly, user involvement, communication and training partially affect that satisfaction on the other hand, the other two sub-dimensions i.e., the involvement of the DG and the implementation strategy does not seem to affect the satisfaction.

It is important to note that future research should be directed towards the new way of "Management Information Systems": evaluating the success of ERP systems. In addition, we can consider further use of research variables in this model.

It seems necessary to consider a more precisely the concept of "quality of engineering change," or override variables to study to eliminate those that are redundant and introduce other variables, such as those relating to culture, user profiles, etc.

So it will be wise to take this model while increasing the sample size to allow better analysis to improve results. This should be possible since the number of Moroccan companies that are in the process of implementing ERP systems is increasing. 


\section{CONCLUSION}

The implementation of an ERP decomposes different things, which is three time horizons: the front project before implementation of the ERP project: during the implementation of ERP and after project after the failover, ownership of ERP.

Given the rapid spread of integrated software packages in the industrialized world, and minority of scientific publications that provide potential answers to questions on the ERP, a research that helps to explain, prior to the implementation of an ERP and its impact on company performance is probably beneficial for academics and professionals to be more successful the implementation of this new innovation.

In conclusion, it should be noted that in our time, "The information system has become the cornerstone of consolidating the company's strategy" (Baumard \& Benvenuti, 1998). Thus, the IS manager is asked "to provide future solutions enabling the company to be more competitive. It is no longer to increase productivity but to provide the general direction the technological know-how through which the company will be able to adapt its service to the needs of its customers while controlling costs "(Baumard \& Benvenuti 1998).

Through this article, it is important to note the prominence that ERP systems are currently in Moroccan companies. In fact, these integrated management systems, which are increasingly "backbone" of the SI of the company, need special attention, including in their implementation and evaluation.

Closer to the work of the "Management Information Systems" relating to the determinants of success of IF including the determinants of user satisfaction, the results of this research show that the dimensions outlined in previous studies (Quality System, quality of information and usefulness) remain well determinants of user satisfaction of an ERP system.

However, the current trend concerning the implementation of ERP systems shows that user satisfaction of a SI especially those ERP systems increasingly depends on more than one dimension as well as organizational managerial: he s 'comes to engineering change. Indeed, it seems that there is an increased importance of the effort required in order to conduct an implementation project of an ERP system, mainly in terms of user involvement, communication and training.

This attempt to develop a new model of success of the evaluation of the ERP system is motivated by the need for businesses to justify and understand their investments in this kind of information technology project. Draft ERP system should not be regarded only as a project of upper management, but a project of organization that integrates all actors and stakeholders, for this reason, in our model of assessment of the success of the ERP system, we take into account the role of all partners and actors of different level of analysis and different phases of the integration of the ERP project.

Three categories of assessment factors have been proposed: the organizational factors, environmental factors, and technological factors. These factors are crucial to assess the success of the project of ERP system; they contribute significantly to understanding the process of the success of the ERP system. The organizations should give more attention to these factors for their successful project of information system and to obtain a high quality system, accepted and used by the employees. As emphasized in our model the success should be evaluated from three main levels of analysis: at the individual level, at the level of the group and of the organization

This research work provides a new tool for the practitioners by allowing them a better understanding of the project of success of the ERP system. The managers of the information system, the direction, and the ERP users need to understand the implication of their actions in the process of success and how they contribute to the improvement of performance. Thus, this work seeks to highlight the suppliers and consultants contributions to perform the ERP project. To cope with more than three-quarters of ERP project fails, organizations must be able to assess their information systems projects. This need led us to investigate this issue by developing a new model that explains the relationship between the partners of the ERP on the one hand, and to propose the main evaluation factors to assess the success of the ERP project.

Notwithstanding, the results presented are limited to enterprises in the sample and should be interpreted with caution in view of the nature and structure of the sample, but also the data collection methods used.

\section{REFERENCES}

[1] DeLone, WH, McLean, ER, 1992. Information Systems Success: The Quest for the Dependent Variable. Information Systems Research 3, 6.95.

[2] Seddon, P. \& Kiew, M, "A partial test and development of the DeLone and McLean model of success", Proceedings of the 15th International Conference on Information Systems, December 14-17, 1994 Vancouver, Canada, pp.99-110.

[3] Marbert, VA, Soni, A. \& Venkataramanan, MA, "An investigation into the ERP in the US industrial companies," French Industrial Management Review, Vol. 19, N. 4, 2000, pp. 5-13.

[4] Davenport, T .., 1998. Putting the Enterprise into the Enterprise System. Harvard Business Review 76, 121-131.

[5] Perotin, P., "Implementation of ERP and organizational integration" 7th Symposium of AIM, Hammamet, 30-1, in June 2002.

[6] Lequeux, JL, Manager with ERP, integrated management software packages and Internal "Les Editions d'Organisation, Paris, 1999

[7] Chand, D., Hachey, G., Hunton, J., Owhoso, V. Vasudevan, S., 2005. A balanced scorecard based framework for Assessing the strategic impacts of ERP systems. Computers in Industry 56, 558-572.

[8] Irani, Z., Sharif, A. Kamal, MM, Love, PED, 2014. Visualising mapping has knowledge of information systems investment evaluation. Expert Systems with Applications 41, 105-125.

[9] Stefanou, CJ, C., 2001. A framework for the ex-ante evaluation of ERP software. European Journal of Information Systems 204-2015.

[10] Uwizeyemungu, S., Raymond, L., 2010. Linking the Effects of ERP to Organizational Performance: Development and Initial Validation of an Evaluation Method. Information Systems Management 27, 25-41.

[11] Urbach, N., Smolnik, S., 2008. A Methodological Examination of Empirical Research on Information Systems Success: 2003 to 2007. Presented at the Proceedings of the Fourteenth Americas Conference on Information Systems, Toronto Canada

[12] Irani, Z., Love, P.E.D., 2008. Evaluating information systems Public and private sector. Elsevier.

[13] Mason, R.O., 1978. Measuring information output: A communication systems approach. Information \& Management 1, 219-234. 
[14] Seddon, P., 1997. A Respecification and Extension of the DeLone and McLean Model of IS Success. Information Systems Research 8, 240253.

[15] Ifinedo, P., 2011. Examining the influences of external expertise and inhouse computer/IT knowledge on ERP system success. Journal of Systems and Software 84, 2065-2078.

[16] Sedera, D., Gable, G.G., 2010. Knowledge Management Competence for Enterprise System Success. The Journal of Strategic Information Systems 19, 296-306.

[17] Bellaaj, M., 2010. Technologies de l'information et performance organisationnelle : différentes approches d'évaluation. (Manuscrit).

[18] Davis, F.D., 1989b. User acceptance of computer technology: a comparison of two theoretical models. Management science 35, 9821003.

[19] Nicolaou, A.I., Bhattacharya, S., 2006. Organizational performance effects of ERP systems usage: The impact of post-implementation changes. International Journal of Accounting Information Systems 7, 18-35.

[20] Markus, M.L., Tanis, C., 2000. the enterprise system experience from adoption to success.

[21] Tsai, W.-H., Hsu, P.-Y., Cheng, J.M.-S., 2006. An AHP approach to assessing the relative importance weights of ERP performance measures. International Journal of management \& enterprise development 3, 351-375.

[22] Kaplan, R.S., Norton, D.P., 1992. The Balanced Scorecard - Measures that Drive Business Perfomance. Harvard Business Review JanuaryFebruary, 71-79.

[23] Mason, R.O., 1978. Measuring information output: A communication systems approach. Information \& Management 1, 219-234.

[24] Rogers, E.M., 1983. DIFFUSION OF INNOVATIONS, 3rd ed. Free Press, United States of America.

[25] DeSanctis, G., Poole, M.S., 1994. Capturing the Complexity in Advanced Technology Use: Adaptive Structuration Theory. Organization Science 15, 121-147.

[26] Bancroft, N., "Implementing SAP/R3: how to introduce a large system into a large organisation”, Manning/prentice Hall, London, UK., 1996 In Adam, F. \& O'doherty, P., "Do ERP Implementations have to be Lengthy? Lessons from IRISH SMEs ", 5ème colloque de l'AIM, Montpellier, 8-10, Novembre, 2000.

[27] Melone, N.P., "A theoretical assessment of the user satisfaction construct in information systems research”, Management Science, Vol. 36, No. 1, 1990, pp. 76-91

[28] Davis, F.D., 1989a. Perceived usefulness, perceived ease of use, and user acceptance of information technology. MIS Quarterly 13, 318-340. 